\title{
Improving the composting of waste materials from agricultural farms, a step towards sustainable agriculture
}

\author{
Ioan Caba. ${ }^{1 *}$, Despina Bordean $^{2}$, Gheorghe Matei ${ }^{3}$, Monica Matei ${ }^{4}$ and Ion Pavel ${ }^{5}$ \\ ${ }^{1}$ INMA Bucharest, Branch Timisoara, Romania \\ ${ }^{2}$ USAMVB Timisoara, Romania \\ ${ }^{3}$ University of Craiova, Romania \\ ${ }^{4}$ INCDPM Bucharest, Romania \\ ${ }^{5}$ INOE 2000- IHP Bucharest, Romania
}

\begin{abstract}
The European Union is working hard to find effective ways for agriculture to remain clean and sustainable. To achieve this objective, the capacity and capability of the research and development system in the agricultural field is increased. Promoting and supporting the development of innovative technologies and their application on agricultural farms of any size or type for sustainable development. The use of innovative technologies for the production of natural fertilizers, besides the complete elimination of the use of chemical fertilizers, is a desideratum to be pursued. Natural fertilizers bring added value in terms of crop yields. Several technical variants of composting from the vegetal waste produced at an agricultural farm are known. Since the cost of obtaining natural fertilizers differs greatly depending on the method chosen. We want to find through this work simple solutions to make the production of natural fertilizers more efficient, solutions that are available to farmers.
\end{abstract}

\section{Introduction}

It is known that in modern agriculture high yields per hectare can only be obtained with the use of chemical fertilizers that are widely used either in liquid or granular form. Once they are administered, reach the soil and by absorption into the root system of the plants, ensuring their more pronounced development. Unfortunately, many of these chemicals also come into groundwater or even in flowing water if they are not being administered on the ground properly. This leads to infestation of nitrite and nitrate waters. Infested drinking water can lead to major health problems for population. An alternative to farmers reach exists, the use of compost obtained on their own farm. Made in its own farms, with raw materials obtained by cultivating technical plants, cereals, and so on, to which organic matter is added as a manure from animals raised on these farms, mixing with

\footnotetext{
*Coresponding author:inmatm_caba@yahoo.com
} 
different types of organic waste also produced in their own households or collected from neighborhood. You can also add to the compost and chopped wood remnants (branches, leaves) or mowing grass. All of these components are well chopped, mixed and left on the ground in the form of a string. This is where microorganisms, bacteria, and different types of fungi work to transform the mixture called compost into an organic fertilizer [1].

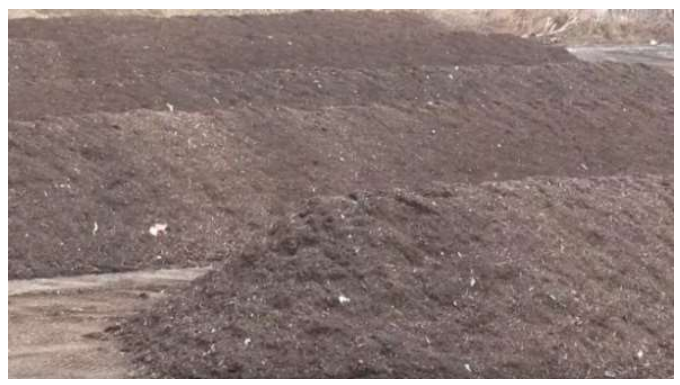

Fig.1. Placement of the mixture of organic materials in the field for composting

Under temperate climates, composting is severely hampered by heavy winters, so composting over time can last between six and nine months. Through this paper, we want to propose simple techniques for speeding up production, so that the batch production period is reduced to about four months, using techniques that are at the fingertips of farmers, avoiding unbearable expenses.

\section{Methodology}

\subsection{Formation and composition of the organic soil}

Disintegration and alteration processes have transformed compact rocks into water and air stores materials, containing simple chemical elements such as salts, oxides and hydroxides, and clay compounds. Together with the water they created conditions for installing the first forms of vegetation. Vegetation transforms the mineral substance into an organic substance by the phenotype of photosynthesis. Thus, a new "organic matter" component [1] appears on the surface and the loose layer of the lithosphere.

Parallel to the photosynthesis process, the process of decomposition of organic matter takes place in nature, especially under the action of microorganisms. The decomposition may be partial when the vegetal debris is transformed into humus or total, when it is called mineralization and the vegetal debris is decomposed to the final products $(\mathrm{CO} 2, \mathrm{H} 2 \mathrm{O}, \mathrm{NH} 3$, NO3-a.s.o)[1].

These processes of synthesis of the organic matter in the mineral matter and of the decomposition of the dead vegetal organisms into the mineral matter, in the nature, realize the so-called "biological circuit of the matter." The biological circuit of the matter consists in the fact that it ensures the permanent resumption of the life process, giving the soil an essential property fertility [1]. Higher plant formations, which provide the synthesis of organic matter together with microorganisms, which cause the decomposition of organic matter, make up biocenoses. Biocenoses are specific to the different environmental conditions [1]. Microorganisms, by way of purchasing the food, are divided into autotrophies and heterotrophs. Autotrophic micro-organisms get their food directly from the mineral matter, using as a caloric energy source, resulting from the chemical processes that take place in the soil. The heterotrophic microorganisms get their food by decomposing organic matter up to simple elements. 


\subsection{The role of organisms in soil formation}

The main groups of microorganisms that activate in the synthesis and decomposition of organic matter are: bacteria, fungi and actinomycetes.

Along with these microorganisms, algae, lichens and animal protozoa microorganisms also contribute to the transformation of organic matter, but to a lesser extent. Vegetable macro organisms, represented by grassy vegetation and woody vegetation, are the ones that synthesize most of the organic matter subject to humification. Animal organisms contribute to the humification process in a much smaller proportion compared to vegetal organisms [2].

\subsection{The origin of organic matter in the soil}

The organic matter in the soil, mostly vegetal, is mainly formed from the debris of the upper plates such as roots, branches, leaves, strains, fruit, seeds, etc. Along with these, but to a much lesser extent, there are animal remains and microorganisms [1].

The amount of organic matter undergoing decomposition processes depends on the type of vegetation and the climatic zone in which it develops.

Under the conditions of our country, the grassy vegetation can leave 10-20 t/ ha of organic residues, mostly from the roots, which are spread within the soil in a thickness of about $100 \mathrm{~cm}$ per year. The annual cultivated plants leave 3-4 t ha organic soil, consisting of roots and stalks of stalks known as stubble. A larger amount of organic remains remains in the soil from alfalfa and clover, which each year bring 3-12 $t$ / ha of roots.

Forest vegetation can leave a quantity of organic mass estimated annually at 2-4 t / ha, mostly on the surface of the soil in the form of a litter. The litter is made up of leaves, branches and bark fragments, having a thickness of 1 to $3 \mathrm{~cm}$ under the woods and 3 to 6 $\mathrm{cm}$ under the hardwood forests [1].

Microorganisms (bacteria, fungi, actinomycetes, etc.) and animals in the soil also bring a significant amount of organic matter, which amounts to 1-4 $t$ / ha per year.

All of these data confirm the statement that we have enough organic raw materials available at any farm for the purpose of composting.

\subsection{Transformation, decomposition of organic residues and composting}

The processes of decomposition of organic residues by microorganisms depend on the nature of debris, environmental conditions and the nature of microorganisms. Organic mattery transformation takes place in three main stages: hydrolysis, oxidation-reduction reactions and total mineralization.

Hydrolysis causes the decomposition of complex organic substances into simpler but organic products. The products resulting from hydrolysis are further subjected to oxidationreduction processes and transformed into either simple organic substances or mineral compounds. Oxido - reduction continues to subject hydrolysis products to intense decomposition processes, resulting in simple organic or even mineral compounds.

Oxide - reducing the hydrolysis products of the protein substances form organic acids, aliphatic acids, alcohols, ammonia, carbon dioxide, water, methane, hydrogen sulphide, a.s.o.

The products resulting from the hydrolysis of the carbonates by oxidation reduction processes are transformed into oxides, volatile organic acids, aldehydes, alcohols, carbon dioxide, water, methane, a.s.o. 
The products resulting from the hydrolysis of lignins and oxidation - reducing substances form phenols, quinones, carbon dioxide, water, a.s.o.

Hydrolysis products of lipids and resins subjected to oxidation reduction processes are converted into unsaturated acids, oxides, volatile organic acids, hydrocarbons, carbon dioxide, water, a.s.o.

Mineralization represents the final phase of decomposition of organic residues and results in the formation of mineral compounds. In the aerobic medium, different acids $\left(\mathrm{HNO}_{2}, \mathrm{HNO}_{3}, \mathrm{H}_{2} \mathrm{SO}_{4}, \mathrm{H}_{3} \mathrm{PO}_{4}\right.$ etc.) are combined with the bases in the soil $(\mathrm{Ca}, \mathrm{Mg}, \mathrm{Na}, \mathrm{K}$ etc) and the corresponding salts result, whereas in the anaerobic environment are obtained as final products: $\mathrm{CH}_{4}, \mathrm{H}_{3} \mathrm{PO}_{4}, \mathrm{H}_{2}$, a.s.o. There are also end products that form under both aerobic and anaerobic mineralization conditions like $\mathrm{Ca}, \mathrm{H}_{2} \mathrm{O}, \mathrm{CO}_{2}, \mathrm{NH}_{3}$.

The decomposition of organic residues is greatly influenced by their composition, taking place rapidly or very slowly, with the formation of intermediate or final products, as will be shown below.

Water-soluble carbonates are easily decomposed into final products $\left(\mathrm{CO}_{2}, \mathrm{H}_{2} \mathrm{O}\right)$.

Water-insoluble carbonates (cellulose and hemicellulose), by hydrolysis, are converted into aminosaccharides and uronic acids, and by oxidation reduction, aldehydes, alkali, carbon dioxide, water, methane, a.s.o. are obtained.

Lignin and tanning substances are very resistant to decomposition, with the tendency of residual accumulation in the soil. By hydrolysis, compounds of the polyphenol type are obtained, and by the oxidation-reduction reactions the polyphenols are passed into phenols and quinones. These intermediate compounds have an important role in the formation of humus.

Protein substances in soil generally break down easily. By hydrolysis they pass into peptides and amino acids, and they are converted to organic acids, fatty acids, alcohols, ammonia, carbon dioxide, water, methane, hydrogen sulphide, a.s.o. by oxidation reduction. Peptides and amino acids, together with phenols and chimes, make up basic compounds that participate in the formation of soil humus.

Fatty substances, waxes and resins slowly break down and hydrolyze pass into glycerin and fatty acids, and oxidation-reducing reactions give rise to unsaturated acids, oxides, volatile organic acids, hydrocarbons, carbon dioxide, water, a.s.o.

\section{General aspects of the properties and composition of the compost}

The compost contains in a balanced form a lot of useful components:

- Mineral elements in a well-assimilated species.

- Enzymes that ensure the transformation of organic residues into nutrients.

- Substances that prevent the spread of pathogens.

- Phytohormones, which improve plant growth and resistance to stress.

This type of organic fertilizer contains 2-4 times more humus than cow dung. Its advantages include good moisture capacity, friability, compatibility with other organic fertilizer types, no significant input energy in production and use. The ability to sell surplus products will allow you to recover costs and get a certain income [3].

\subsection{Compost production}

In the conventional composting world, the unwritten rule is that one ton of inputs results in $0.75 \mathrm{~m} 3$ of compost, the weight of which varies depending on the moisture content, but is usually about $0.5 \mathrm{t}$. In other words, $50 \%$ of the mass is lost, part of the nitrogen is lost as 
ammonia, but if the process is well managed, the loss of nitrogen is minimal. This varies depending on the nature of the inputs and the system used. The higher the ratio of carbonrich materials to those rich in nitrogen, the higher the final product weight as a percentage of the input weight [4].

Of course, the final weight and volume of the product varies depending on the origin of the food, the loom used, etc., but the above-mentioned intuitive rule is a handy method to quickly calculate production [5].

In composting, mixtures of nitrogen and carbon-rich materials are made at first and nothing is added afterwards. We can also use the raw material and shredded paper or cardboard, compost can be converted with a small (in volume) of 5\% poultry manure [4].

The result of this process is a weight of the finished product closer to $50 \%$ of the initial input weight.

To produce compost we need some living conditions:

- hospitable living environment;

- source of food;

- adequate humidity (water content greater than $50 \%$ by weight);

- appropriate aeration;

- extreme temperature protection.

Some materials are suitable to create a good environment for composting, while others lack one or more of the above features and must be used in different combinations. Table 1 provides some data on the absorption of each material, the leaching potential and the carbon-nitrogen ratios $(\mathrm{C}: \mathrm{A})$ that can be obtained from composting.

Table 1. Materials used for composting

\begin{tabular}{|c|c|c|c|c|}
\hline $\begin{array}{c}\text { No. } \\
\text { crt. }\end{array}$ & Material & Absorption & $\begin{array}{c}\text { Loosening } \\
\text { Potential }\end{array}$ & $\begin{array}{c}\text { C/A } \\
\text { Report }\end{array}$ \\
\hline 1. & Animal manure & medium-good & good & $22-56$ \\
\hline 2. & Domestic waste & good & medium & 58 \\
\hline 3. & Silage corn & medium-good & medium & $38-43$ \\
\hline 4. & Hay & low & medium & $15-32$ \\
\hline 5. & Straw & low & medium-good & $48-150$ \\
\hline 6. & $\begin{array}{c}\text { Paper from the municipal } \\
\text { waste stream }\end{array}$ & medium-good & medium-good & $127-178$ \\
\hline 7. & Bark hard essence & low & good & $116-436$ \\
\hline 8. & Bark soft essence & low & good & $131-1280$ \\
\hline 9. & Corrugated cardboard & good & medium & 563 \\
\hline 10. & Waste paper fibers & medium-good & medium & $45-250$ \\
\hline 12. & Sawdust & low-medium & low-medium & $142-750$ \\
\hline 13. & Strong wood chips & low & low & $451-819$ \\
\hline 14. & Soft wood chips & low & low & $212-1313$ \\
\hline 15. & Leaves (dry, free) & low-medium & low-medium & $40-80$ \\
\hline 16. & Corn strains & low & good & $60-123$ \\
\hline
\end{tabular}

If available, crushed paper or paperboard is an excellent component, especially when combined with typical organic resources in the farm, such as straw and hay. However, organic producers should be careful and ensure that such materials are not restricted in accordance with their organic certification standards [4].

Other material in this category is the paper-making residue with a high absorption capacity and small particle size that perfectly complements the high ratios and also has good aggregation properties of straw, hay, shrubs, or shavings [6,7]. In general, it should be noted that the selection of compost materials and their mixing in the necessary quantities is the key to success. 
Recipient blends used to create compost are essential in achieving a bio-quality fertilizer. They offer protection in the event of extreme temperatures, the necessary level and consistency of humidity and an adequate supply of oxygen. Fortunately, given their critical importance in the process, good mixes are generally easy to find on farms. The most difficult criterion to satisfy adequately is usually absorption, because most straw and even hay are not good at retaining moisture. This can be easily addressed by mixing sweepings from cattle, horses or sheep with straw.

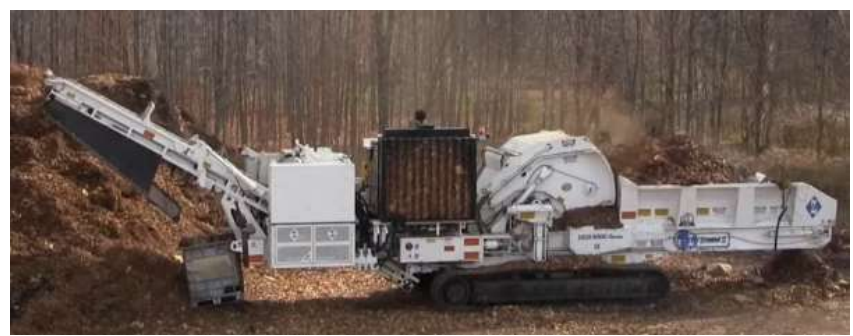

Fig. 2. Crushing and mixing the raw materials used to make the cores

The process of creating compost mixtures should not be a burden, it can be done manually with a fork (small operations), a bucket tractor (larger operations), a technological trailer for mixing the feed or, if necessary, the shredders of large plant waste.

The latter equipment would be suitable only for large commercial composting operations where a high level of product efficiency and quality is required [6,7].

There are regions where seaweed, human biowastes from purification stations of large localities, etc. are used as raw material for the composting.

\subsection{Humidity}

The mixture of material used in composting must be capable of retaining sufficient moisture as the microorganisms and bacteria have a favorable environment in which they can live and multiply. A moisture content of less than $50 \%$ is dangerous. Except for extreme heat or extreme cold, the lack of adequate humidity may stop or increase the duration of composting.

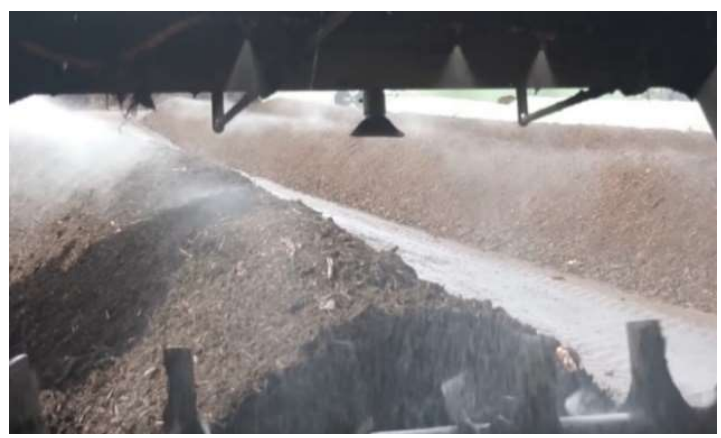

Fig. 3. Wetting the compost during the aeration operation.

The range of ideal moisture content for materials in conventional composting systems is between $45-60 \%$, depending on the geographical area and the multi-annual climate $[4,5,8]$. 


\subsection{Aeration of compost}

Aeration (passive or forced) has many different functions during the composting process:

- supply of oxygen to keep microorganisms alive

- removal of carbon dioxide

- reducing water to allow material to dry

- temperature control to prevent values higher than $70{ }^{\circ} \mathrm{C}-80{ }^{\circ} \mathrm{C}$

The need for oxygen depends on the activity of the microorganisms. Very important for the supply of oxygen is the mixture of materials introduced into the heap, especially the quantity, but also the size and distribution of the interstices. During the process of composting, the oxygen concentration in the pile decreases. To supply more oxygen, ventilation or material returns are used. Ventilation systems either force the air to enter the heap so that the pressure in the interior is higher than that in the outside environment, or it reduces the pressure in the heap.

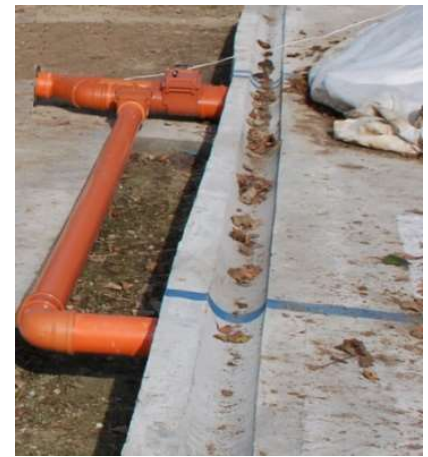

Fig. 4. Tube for ventilation of compost.

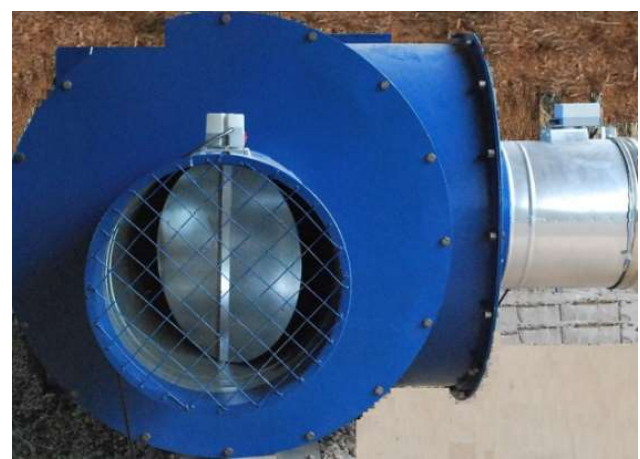

Fig. 5. Ventilator

Both systems can increase the concentration of oxygen in the heap by mechanically pumping the air. The return of the material is also a possibility for increasing the oxygen concentration. The turntable can be turned manually or using mechanized devices. The combination of natural aeration and the return of compost piles is a very good method. During winter it is recommended to use the aeration duct for the advantages of mechanical devices:

- there is no need to return the snow covered area;

- warm-air compost produced by solar panels can be heated without cost, keeping microorganisms active, reducing the time required for composting;

- the fan can operate with current obtained from photovoltaic panels, green current, without current costs, without using the national distribution network;

- usability on any part of the farm.
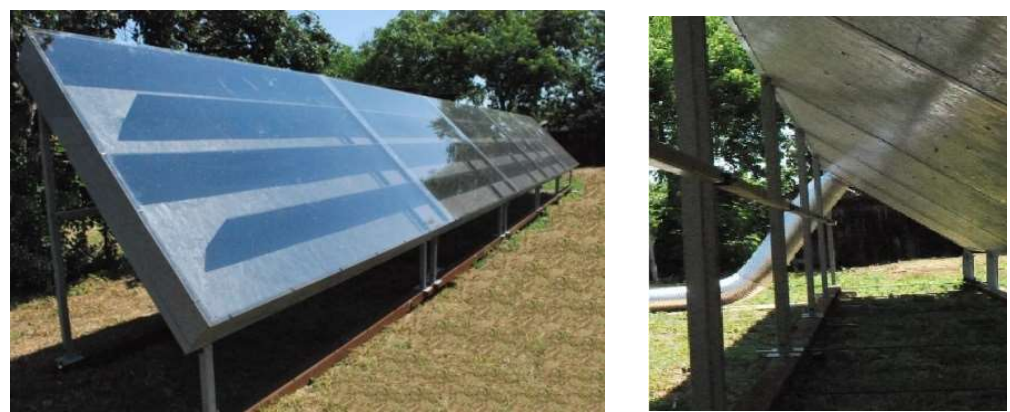

Fig. 6. Panels for heating the air mass circulated during aeration of compost. 


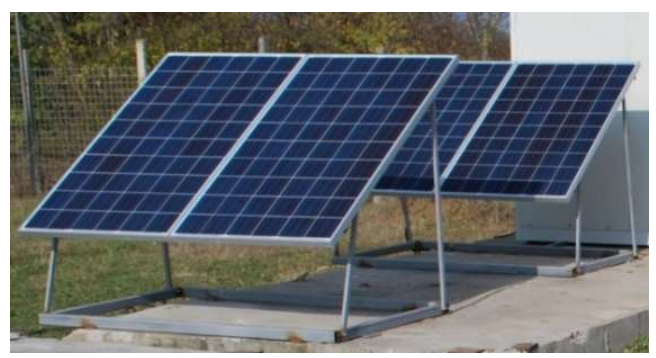

Fig. 7. Photovoltaic panels

\subsection{Digestion of the compost}

The optimum digestion for the corresponding composting activity is the total porosity of $48-60 \%$, of which capillary porosity of $30-36 \%$ and of non-capillary (aeration) of $18-24 \%$. At this level, the compost contains $1 / 3$ air and 2/3 water. The apparent density of the compost under these conditions is between 1.0 and $1.4 \mathrm{~g} / \mathrm{cm} 3$ of the "seated" soil.

A properly worked soil, $50-150 \mathrm{~kg} / \mathrm{ha}$ of nitric nitrogen accumulates through the activity of nitrifying microorganisms and $23-55 \mathrm{~kg} /$ ha of nitrogen through the activity of nitrogen fixation bacteria. In a too loose soil, the process of aeration and intense mineralization of organic matter and soil humus increases, an unwanted phenomenon.

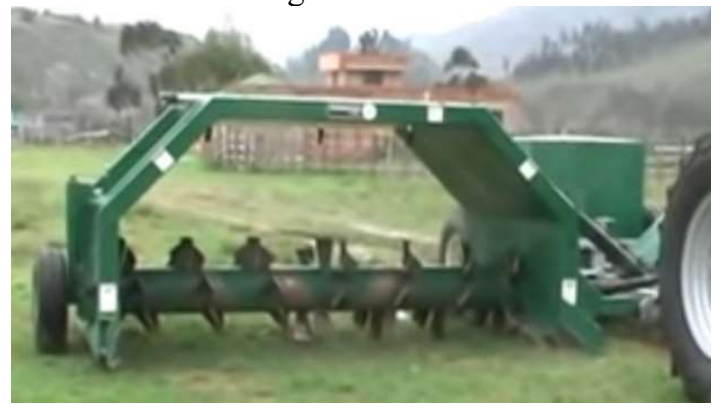

Fig.8. Towing machine for loosening and wetting the compost.

\subsection{Temperature control}

Active organisms are producing thermal energy. This energy is measurable in turn. By setting the temperature inside the heap, we can conclude as much time as possible until the composting process is complete. The temperature of the external environment also influences the decomposition process. The rate of decomposition is determined by the internal temperature of the compost, as the activity of the microorganisms increases with the temperature increase, which should never pass $80{ }^{\circ} \mathrm{C}$. Temperature is an appropriate value for determining the degradation phase and the degree of decomposition of compost. The curve characteristic of temperature variation is presented according to time passage, (fig. 9), which does not exceed 6 months. Through additional storing, aeration and wetting activities, this range can be reduced to almost 4 months. 


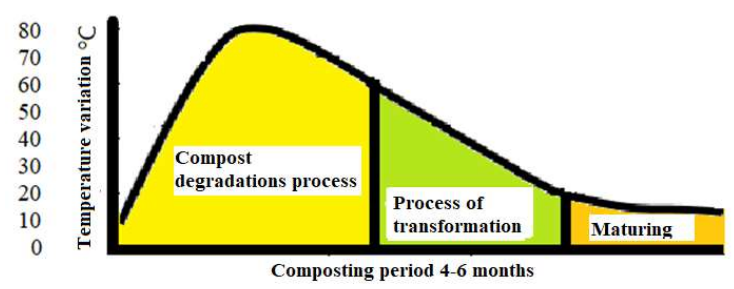

Fig. 9. Variation of compost temperature over time

\section{$3.6 \mathrm{pH}$ level}

The activity of microorganisms is closely related to the $\mathrm{pH}$ level of the substrate introduced. Good for biological activity are $\mathrm{pH}$ values ranging from 7 to 11 .

If the passes below 7 lead to a reduction in speed in the first stages of the process. If the $\mathrm{pH}$ is below 5, it may notice a strong inhibition in the initial phase (up to rapid temperature rise). Therefore, the period between collection, storage and commencement of treatment at the station should be short. Lack of adequate oxygen during collection and storage leads to an uncontrolled natural anaerobic digestion, which causes low $\mathrm{pH}$ values $[9,11]$.

\subsection{Carbon / nitrogen ratio}

The ratio of carbon to nitrogen (not specific analyzes carried out in a specialized laboratory) compost material influences the rate of decomposition process. The optimal carbon ratio $(\mathrm{C})$ : nitrogen $(\mathrm{N})$ should be between 1 and 35: 1 . If the proportion is below 10 : 1 , growth is inhibited by the lack of carbon, and if it exceeds 40: 1, too little nitrogen is available. Outside these limits 1:10 and up to 40: 1, the microorganism cannot grow and grow. In fact, the activity of these microorganisms is unchanged, but without an increase in population the time required for the composting process expands, an unwanted phenomenon [10,11].

\section{Conclusions}

Based on the data and materials submitted, composting is an environmentally beneficial process that has great potential as a component of organic and sustainable agriculture. Agricultural specialists claim that the fertilizer thus obtained is one of the best fertilizers because it contains concentrations of beneficial bacteria and other microorganisms, biologically active stimulants for plants [10]. The product contains the necessary set of macro and micro nutrients, enzymes, soil antibiotics, vitamins, growth hormones and humic substances. The compost contains nitrogen, phosphorus, potassium, calcium and a host of beneficial microorganisms and bacteria than those we usually find in the upper layers of the soil. It is used as a natural fertilizer for soil being mixed with earth. In contrast to chemical fertilizers that feed the plant directly, but damages the soil, matured compost enriches the fertility of the soil as a whole [12].

Using compost generates multiple benefits for farmers:

- most of the waste and vegetal remains and animal manure present on an agricultural farm are used without costly investment in raw materials;

- significant production increases are achieved because plants easily assimilate nutrients;

- water retention increases in soil (the amount of water required for irrigation decreases by about $30 \%$ );

- it is not toxic, does not burn plants, has no restrictions on use, can be used in any crop, greenhouse or field, with excellent results; 
- the compost obtained can be used directly on the farm by distributing it on the surface of the plant, reducing or even eliminating the investment in the purchase of traditional fertilizers (fungicides, insecticides, etc.).

- rebuild soils affected by long-term use of chemicals. By repeated application, the soil will be completely repopulated with the microorganisms beneficial to the plants destroyed by chemicals used over the years.

- the application of compost improves the soil structure, aerates the soil and makes it easy to process, which reduces the cost of fueling the agricultural machinery, indirectly reduces soil compaction through multiple passes.

- the administration of the compost does not require investments in new machinery, it is possible to use the existing ones on the agricultural farms: solid chemical fertilizer machines, wood scraping machines, forage mixers, etc.

\section{Acknowledgement}

This work was supported by a grant of the Romanian Research and Innovation Ministry, through Programme 1 - Development of the national research-development system, subprogramme 1.2 - Institutional performance - Projects for financing excellence in RDI, contract no. 16PFE.

\section{References}

1. N. Bernier, J.F. Ponge, Dynamic formation of humus during silvicogenetic cycle in a mountain spruce forest, Soil Biology and Biochemistry J., (1994)

2. R. Hempfling, H. R. Schulten, R. Horn, Relevance of humus composition to physical / mechanical stability of agricultural soils: a mass spectrometry and direct pyrolysis study, Analytical and Applied Pyrolysis J., (1990)

3. P. Bogdanov, Commercial vermiculture: how to build a prosperous business with red rum, VermiCoPress J., Oregon, U.S.A. (1996)

4. GEORG, The feasibility of organic and transitional organic farming development for the processing of organic waste and municipal waste using large-scale vermicompostation, Organic Earth Resource Group, Halifax, Nova Scotia, Canada, (2004)

5. R. Rink., Farm composting guide, Ed. Natural Resources Service, Agriculture and Engineering, NRAES-54, (1992)

6. C. Elvira, M. Goioechea, et al., Bioconversion of sludge solids from cellulose-paper through earthworms, Bioresources Technology J., UK, (1996)

7. C. Elvira, L. Sampedro, Vermicomposing of sewage sludge in the paper industry through nitrogen-rich materials, Biochim. Bio. Sol. J., (1997)

8. J.Dominguez, C. A Edwards, Effects of stocks and moisture content on growth and maturation in Eisenia andrei (Oliogochete) in pork waste, Biochim. Bio. Ground J., (1997)

9. W. Bidlingmaier, Biologische Verwertungstechnologien, C. S., D. for W. M. - Bauhaus Weimar U., G., Deutschland, (2009)

10. Canellas, et al., Humic acids isolated from earthworm compost amplifies root elongation, side roots and $H+-$ ATPase activity of the plasma membrane in maize roots, Plant Physiology J., (2002)

11. C. Bachert, W. Bidlingmaier, S. Wattanachira, Handbook on the production of compost in graded uncovered strings, E. C. N., Weimar G., ISBN 3-935974-23, (2008)

12. I. Voicea, V. Vladuţ, P. Cardei, M. Matache, I. Gageanu, Gh.Voicu, C. Popescu, G. Paraschiv, O. Kabas, Compacting process and mathematical analysis of miscanthus briquettes expansion, Proceedings of The 43 International Symposium on Agricultural Engineering "Actual Tasks on Agricultural Engineering", Opatija - Croatia, pag. $667 \div 676$, (2015). 